\title{
The association between dietary antioxidant indices and cardiac disease: Baseline data of Kharameh cohort
}

parisa keshani

Shiraz University of Medical Sciences

Maryam jalali

Shiraz University of Medical Sciences https://orcid.org/0000-0003-3319-2048

masomeh ghoddusi ( $\sim$ m.ghoddusi94@yahoo.com )

ramin rezaeianzadeh

Shiraz University of Medical Sciences

Seyed Vahid Hosseini

Shiraz University of Medical Sciences

Abbas rezaeianzadeh

Shiraz University of Medical Sciences

\section{Research}

Keywords: Antioxidants, Cardiac disease, Dietary intake, Dietary antioxidant index, Dietary antioxidant quality

Posted Date: February 15th, 2022

DOI: https://doi.org/10.21203/rs.3.rs-1313935/v1

License: (c) (1) This work is licensed under a Creative Commons Attribution 4.0 International License. Read Full License 


\section{Abstract}

\section{Background:}

Oxidative stress contributes to the development of cardiovascular disease. Tools for evaluating the antiinflammatory and antioxidative characteristics of an individual's diet as a whole may be valuable for assessing the combined effects of dietary antioxidants on health. This population-based study aimed to investigate the association between dietary antioxidants and cardiac disease.

\section{Methods:}

In this population-based cross-sectional study, 10439 individuals aged 40-70 years were recruited during 2014-2017 in Kherameh cohort study which is a part of the Prospective Epidemiological Research Studies in Iran (PERSIAN). The food frequency questionnaire (FFQ) with 130 food items was used to assess the dietary intakes. Vitamin A, E, C, selenium, zinc and Manganese intakes were used to compute dietary antioxidant index (DAl) and dietary antioxidant quality score (DAQs).

\section{Results:}

The participants' mean age was $52.1 \pm 8.3$ years. Among all, 4356 (41.7\%) were overweight and 1892 (18.1\%) were obese. According to the results, odds of cardiac diseases decreased by increasing DAl score $(\mathrm{OR}=0.80$, Pvalue $<0.001)$, Odds of cardiac diseases increased by lower DAQS after adjusting for demographic variables including age, sex, BMI, Marital status and hypertension (OR=0.799, $\mathrm{P}$ value $=0.002$ )

\section{Conclusion:}

The role of anti-oxidants in reducing the odds of cardiovascular disease is very important. Our results highlighted that DAQS and DAI had protective effect on the odds of cardiovascular disease. Therefore, it is suggested that anti-oxidants as zinc, manganese, selenium, and vitamins $A, E$ and $C$ should be taken through food to reduce the risk of the disease.

\section{Introduction}

Cardiovascular diseases (CVDs) account for almost a third of all deaths per year worldwide (Organization, 2021). The prevalence of CVD cases reached 523 million in 2019, a figure almost twice as much as that reported in 1990. Also, the frequency of deaths related to CVD reached 18.6 million in 2019, representing about 50\% rise from the 12.1 million recorded in 1990 (Roth et al., 2020). Most of the deaths from CVD occur in developing countries (World Health Organization, 11 June 2021). In Iran, it is the main cause $(46 \%)$ of death, accounting for roughly a fifth of the burden from diseases and causing a million disability-adjusted life years (DALYs) (Sarrafzadegan and Mohammmadifard, 2019). Fortunately, some risk factors for CVD are modifiable, the most notable of which being an unbalanced diet, lack of exercise, smoking, and alcohol consumption (Organization, 2021). 
Oxidative stress contributes to the development of a wide range of diseases, among which CVDs can be mentioned. Thus, it is reasonable to say that preventing the formation of reactive oxygen species (ROS) can contribute to preventing and treating certain health disorders.

Nutrients and other substances with free radical scavenging properties are known as antioxidants (Lorenzon dos Santos et al., 2020) (Wright et al., 2004). Some examples are selenium, zinc, and vitamins $A, C$ and $E$, which are known to reduce CVD and mortality, with a possible role in promoting endogenous antioxidative processes (Jenkins et al., 2020). So far, most researchers have looked at isolated nutrients when attempting to determine the possible links between antioxidants and health. However, antioxidant nutrients are consumed in different combinations as part of the meals that constitute an individual's diet (Rivas et al., 2012). Hence, some tools including the Dietary Antioxidant Index (DAI) and Dietary Antioxidant Quality Score (DAQS) (LuuHung, 2015) have emerged for evaluating the anti-inflammatory and antioxidative characteristics of an individual's diet as a whole; they. These tools may be valuable for assessing the combined effects of dietary antioxidants on indices related to health (LuuHung, 2015). Using these tools in this population-based study, we sought to investigate the association between dietary antioxidants and CVD risk.

\section{Material And Method}

\section{Study population}

This is a cross-sectional population-based study in which 10439 individuals aged 40-70 years were enrolled during 2014-2017 in Kherameh cohort study which is a part of the Prospective Epidemiological Research Studies in Iran (PERSIAN Cohort). Its aim and design had been previously published (Poustchi et al., 2018). The primary aim of this cohort study was calculating the prevalence and risk factors of noncommunicable diseases. Patients with a a history of positive atherosclorotic status via angiography psocedure were selected as the participants in this study. Atherosclerosis is defined as arterial degeneration related to increased fat aggregation in the arterial walls and augmentation of vascular stiffness (Lorenzon dos Santos et al., 2020).

The exclusion criteria in this study were unwillingness to cooprate in evaluation, intellectual disability, and lack of tendency to participate in the study. Additionally, participants with a total daily energy intake in the range of mean $\pm 3 S D$ were considered as over-report data and excluded. (Rezazadeh et al., 2010, Zamani et al., 2013).

\section{Measurements}

\section{Dietary and physical activity assessment}

As a reliable and valid tool, food frequency questionnaire (FFQ) with 130 food items was applied to assess the participans' dietary intake (Poustchi et al., 2018). The frequency of consumption of each food item was asked by expert dieticians through face-to-face interview. The participants reported their 
consumption of each food item in the past year on a monthly, weekly, or daily scale. After data gathering, all the findings were converted to the scale of daily intake. Finally, Nutritionist IV software modified for Iranian foods (version 7.0; N-Squared Computing, Salem, OR, USA) was used to analyze food items for their macro- and micro-nutrient content(Mirmiran et al., 2010).

physical activity was assessed using a questionnaire which included sports, occupation, and sleeping duration and eating in a day. Finally, the Metabolic Equivalent Task (MET) index was computed. Body Mass Index (BMI) was calculated by dividing weight by height squared (Rezaianzadeh et al., 2021).

\section{Measurement of dietary antioxidant quality score (DAQS)}

Some minerals and vitamins with antioxidant functions such as selenium, zinc, Manganese, and vitamins $A, E, C$, were used to compute DAQs (LuuHung, 2015).

For computing DAQS in this study, the first step was to compare the daily intake of nutrient to the recommended daily intake (RDI) (Bistrian, 2006). We applied the Tur et al.'s (Tur et al., 2005) method to allocate a value of 0 or 1 to every subject's antioxidant intake. In this method, when the intake was less than $2 / 3$ of the RDI, the value of 0 was allocated to it, and if the intake was more than $2 / 3$ of the RDI, the value of 1 was assigned to it. Total DAQS was calculated as the sum of these value intakes, so it ranged from 0 (very poor quality) to 6 (high quality (Shahinfar et al., 2020b). For estimating the risk of inadequate intake, the proportion of individuals with intakes less than $2 / 3$ of the RDI was computed (Aranceta et al., 2001).

\section{Assessment of Dietary Antioxidant Index (DAl)}

In this study, DAl was calculated based on the Wright's method (LuuHung, 2015). For this purpose, vitamins $A, C$ and $E$, selenium, manganese, and zinc were each standardized by subtracting the global mean and then dividing them by the global SD. Then, the DAI was obtained by summation of the standardized intakes; the formula is as follows (Vahid et al., 2021b):

DAI $=\sum_{i=1}^{n=6} \frac{\text { individualintake }- \text { Mean }}{S D}$

\section{Statistical analysis}

For quantitative variables, Mean \pm SD and for qualitative ones frequency (\%) are reported. The main outcome in our study was atherosclerosis disease. Logistic regression analysis was applied for evaluating the association between cardiac disease, DAI and DAQS score after adjusting for covariates like age, sex, BMI, marital status, cigarette smoking, and hypertension. Odds ratio (OR) and confidence interval were estimated using the Statistical Package for Social Sciences (SPSS version 22; SPSS Inc., Chicago, IL, USA). We considered $p<0.05$ as statistically significant.

\section{Results}


A total of 10439 participants with a mean age of $52.1 \pm 8.3$ years were included; of them, $43.4 \%$ and $56.6 \%$ were male and female, respectivley. 419 subjects (40.1\%) had normal BMI (18.5-24.9 kg/m²), 4356 $(41.7 \%)$ were overweight $\left(25-29.9 \mathrm{~kg} / \mathrm{m}^{2}\right)$, and $1892(18.1 \%)$ were in the obese category $(\mathrm{BMI} \geq 30)$. Table 1 shows the demographic information of the participants. ORs and $95 \% \mathrm{Cls}$ for the odds of cardiac diseases are shown in Table 2. According to the results, odds of cardiac diseases decrease by increasing DAl score $(\mathrm{OR}=0.80, \mathrm{P}$ value $<0.001)$.

Table1: Demographic characteristics and dietary intake of nutrients for participants with or without cardiac disease 


\begin{tabular}{|c|c|c|c|c|c|}
\hline \multicolumn{2}{|l|}{ Characteristics } & Total & $\begin{array}{l}\text { Cardiac } \\
\text { disease }\end{array}$ & $\begin{array}{l}\text { No Cardiac } \\
\text { disease }\end{array}$ & $\begin{array}{l}P \\
\text { value }\end{array}$ \\
\hline \multicolumn{2}{|l|}{$\mathrm{Age}^{*}$} & $52.1 \pm 8.3$ & $56.4 \pm 7.8$ & $50.7 \pm 7.9$ & $<0.001$ \\
\hline \multicolumn{2}{|l|}{ Physical activity* } & $2395.3 \pm 714.4$ & $36.9 \pm 6$ & $38.6 \pm 6.1$ & $<0.001$ \\
\hline \multirow[t]{2}{*}{ Gender** } & male & $4527(43.4)$ & $439(9.7)$ & 4088(90.3) & \multirow[t]{2}{*}{0.67} \\
\hline & female & $5912(56.6)$ & $588(9.9)$ & $5324(90.1)$ & \\
\hline \multirow[t]{2}{*}{ Marital status** } & single & 1162(11.1) & $168(14.5)$ & $994(85.5)$ & \multirow[t]{2}{*}{$<0.001$} \\
\hline & married & 9277(88.9) & $859(9.3)$ & $8418(90.7)$ & \\
\hline \multirow[t]{3}{*}{$\mathrm{BM}{ }^{\star \star *}$} & normal & $4191(40.1)$ & $338(8.1)$ & 3853(91.9) & \multirow[t]{3}{*}{$<0.001$} \\
\hline & overweight & $4356(41.7)$ & $461(10.6)$ & 3895(89.4) & \\
\hline & obese & 1892(18.1) & $228(12.1)$ & 1664(87.9) & \\
\hline \multirow[t]{2}{*}{ Employement } & yes & $5325(51)$ & $393(7.4)$ & 4932(92.6) & \multirow[t]{2}{*}{$<0.001$} \\
\hline & no & $5114(49)$ & $634(12.4)$ & $4480(87.6)$ & \\
\hline \multicolumn{2}{|c|}{$\begin{array}{l}\text { Vitamin A intake ( } \mu \mathrm{g} / \text { day } / 1,000 \\
\text { kcal) }\end{array}$} & $9663.1 \pm 5197.4$ & $9460.8 \pm 5017.4$ & $9685.2 \pm 5216.4$ & 0.2 \\
\hline \multicolumn{2}{|c|}{$\begin{array}{l}\text { Vitamin C intake (mg/day/1,000 } \\
\text { kcal) }\end{array}$} & $119.5 \pm 61.8$ & $116.4 \pm 59.1$ & $119.9 \pm 62.1$ & 0.07 \\
\hline \multicolumn{2}{|c|}{$\begin{array}{l}\text { Vitamin E intake (mg/day/1,000 } \\
\text { kcal) }\end{array}$} & $7.5 \pm 3$ & $7.2 \pm 2.9$ & $7.5 \pm 3$ & 0.001 \\
\hline \multicolumn{2}{|c|}{ Zinc intake (mg/day/1,000 kcal) } & $9.8 \pm 3$ & $9.2 \pm 3.2$ & $9.9 \pm 3.3$ & $<0.001$ \\
\hline \multicolumn{2}{|c|}{$\begin{array}{l}\text { Selenium intake ( } \mu \mathrm{g} / \text { day } / 1,000 \\
\text { kcal) }\end{array}$} & $107.5 \pm 41.6$ & $99.4 \pm 41.4$ & $108.4 \pm 41.6$ & $<0.001$ \\
\hline \multicolumn{2}{|c|}{$\begin{array}{l}\text { Manganese intake (mg/day/1,000 } \\
\text { kcal) }\end{array}$} & $4.8 \pm 2.1$ & $4.6 \pm 2$ & $4.8 \pm 2.1$ & $<0.001$ \\
\hline \multicolumn{2}{|l|}{ Energy intake } & $38.4 \pm 6.1$ & $2235.2 \pm 724.9$ & $2412.7 \pm 711.1$ & $<0.001$ \\
\hline \multicolumn{2}{|l|}{ DAl score } & & & & - \\
\hline \multicolumn{2}{|l|}{ DAQ score } & & & & - \\
\hline
\end{tabular}

*Values reported as mean \pm standard deviation. **Values reported as number (\%). P values in bold indicate numbers that are significant ( $P$ value $<0.05)$.

$\mathrm{BMI}$, body mass index; DAl, dietary antioxidant index; DAQ, dietary antioxidant quality 
Table 2

Association between cardiac disease and DAl after adjustment for covariates

\begin{tabular}{|c|c|c|c|c|}
\hline \multicolumn{2}{|l|}{ Characteristics } & OR & $95 \% \mathrm{Cl}$ & $P$ value \\
\hline \multicolumn{2}{|l|}{ DAl } & 0.80 & $(0.78,0.83)$ & $<0.001$ \\
\hline \multicolumn{2}{|l|}{ Age } & 1.07 & $(1.06,1.08)$ & $<0.001$ \\
\hline \multirow[t]{2}{*}{ Gender } & male & \multirow[t]{2}{*}{1.58} & \multirow[t]{2}{*}{$(1.34,1.58)$} & \multirow[t]{2}{*}{$<0.001$} \\
\hline & Female* & & & \\
\hline \multirow[t]{4}{*}{ BMI } & & & & \multirow[t]{2}{*}{0.002} \\
\hline & Normal* & & & \\
\hline & Overweight & 1.24 & $(1.06,1.46)$ & 0.007 \\
\hline & Obese & 1.42 & $(1.16,1.74)$ & 0.001 \\
\hline \multirow[t]{2}{*}{ Hypertension } & Yes * & \multirow[t]{2}{*}{0.24} & \multirow[t]{2}{*}{$(0.18,0.25)$} & \multirow[t]{2}{*}{$<0.001$} \\
\hline & No & & & \\
\hline \multirow[t]{2}{*}{ Marital status } & single & \multirow[t]{2}{*}{1.19} & \multirow[t]{2}{*}{$(.96,1.47)$} & \multirow[t]{2}{*}{0.11} \\
\hline & Married* & & & \\
\hline
\end{tabular}

Association between cardiac diseases and DAQs is also displayed in Table 3. DAQs is categorized based on median. When the analysis was done with dichotomous DAQs and adjustment of demographic variables including age, sex, BMI, marital status and hypertension, the odds of cardiac diseases were more in the category with lower DAQS intake $(\mathrm{OR}=0.799, \mathrm{P}$ value $=0.002)$ 
Table 3

Association between cardiac disease and DAQs after adjustment for covariates

\begin{tabular}{|c|c|c|c|c|}
\hline characteristics & & OR & $95 \% \mathrm{Cl}$ & $P$ value \\
\hline \multirow[t]{2}{*}{ DAQs } & $<$ Median & \multirow[t]{2}{*}{0.799} & \multirow[t]{2}{*}{$(0.69,0.92)$} & \multirow[t]{2}{*}{0.002} \\
\hline & $>$ Median* & & & \\
\hline Age & & 1.07 & $(1.06,1.08)$ & $<0.001$ \\
\hline \multirow[t]{2}{*}{ Gender } & Male & \multirow[t]{2}{*}{1.49} & \multirow[t]{2}{*}{$(1.27,1.75)$} & \multirow[t]{2}{*}{$<0.001$} \\
\hline & Female* & & & \\
\hline \multirow[t]{4}{*}{ BMI } & & & & \multirow[t]{2}{*}{0.004} \\
\hline & Normal* & & & \\
\hline & Overweight & 1.23 & $(1.05,1.44)$ & 0.01 \\
\hline & Obese & 1.39 & $(1.16,1.74)$ & 0.001 \\
\hline \multirow[t]{2}{*}{ Hypertension } & Yes * & \multirow[t]{2}{*}{0.21} & \multirow[t]{2}{*}{$(0.19,0.25)$} & \multirow[t]{2}{*}{$<0.001$} \\
\hline & No & & & \\
\hline \multirow[t]{2}{*}{ Marital status } & Single & \multirow[t]{2}{*}{1.19} & \multirow[t]{2}{*}{$(0.96,1.42)$} & \multirow[t]{2}{*}{0.1} \\
\hline & Married* & & & \\
\hline \multicolumn{5}{|c|}{ *Shows reference category } \\
\hline \multicolumn{5}{|c|}{ BMI, body mass index; DAQ, dietary antioxidant quality } \\
\hline
\end{tabular}

\section{Discussion}

This population-based study aimed to investigate the association of dietary antioxidants (measured by DAI and DAQ scores) and CVD risk. According to our findings, the risk of CVDs can be minimized by boosting the amount of antioxidants in an individual's diet.

Oxidative stress contributes to the development of a wide range of diseases, among which those related to atherosclerosis can be mentioned. Atherosclerosis is a vascular disorder that develops as a result of chronic inflammation, with oxidized low-density lipoprotein (oxLDL) and endothelium dysfunction, which have vital roles in its pathogenesis. The progression of atherosclerosis is signaled by oxLDL aggregation in the arterial wall (22). It is known that oxidative stress and inflammatory activity are associated with oxLDL accumulation and endothelial dysfunction ( $L i$ and Yang, 2018). Hence, it is plausible that by minimizing the generation of free radicals, CVDs like atherosclerosis can be prevented and treated (Lorenzon dos Santos et al., 2020). 
Various nutritional antioxidants work against atherosclerosis, either by promoting endogenous antioxidant activity or directly scavenging free radicals (Lönn et al., 2012). Some examples are selenium, zinc, vitamins $\mathrm{C}$ and $\mathrm{E}$, manganese, flavonoids, and carotenoid compounds. While most studies have looked at the health-promoting effects of these nutrients in isolation, few have investigated their combined impacts within different diets (LuuHung, 2015). When combined, dietary antioxidants may interact to provide various overall effects, which is why tools like the DAI and DAQ have been designed and implemented (Vahid et al., 2020). Some studies have assessed the relationship of the DAl with the TAC and markers of inflammation (Vahid et al., 2020, LuuHung, 2015). Notably, scores related to dietary antioxidant content as evaluated by these tools were inversely related to the levels of inflammatory factors like IL-1 $\beta$ and TNF- $a$, explaining the possible biochemical pathway through which an antioxidantrich diet can lead to improved health outcomes like decreased mortality and CVD risk (LuuHung, 2015).

\section{Micronutrients and cardiovascular diseases}

Although it is known that selenium acts as a cofactor of antioxidative enzymes like glutathione peroxidase (GSH-Px), its cardioprotective impact remains a matter of controversy. One study observed a $24 \%$ fall in CVD risk with a 50\% rise in blood selenium levels (Flores-Mateo et al., 2006). Nonetheless, selenium offers no significant protection against all-cause mortality, CVD mortality, or adverse cardiovascular events, according to meta-analyses and systematic reviews (Cammisotto et al., 2021, Rees et al., 2013, Flores-Mateo et al., 2006). Jenkins et al. concluded that the inclusion of this mineral in an antioxidative diet was important to promote cellular antioxidant activity if antioxidative supplements were to provide their health-promoting effects (Jenkins et al., 2020).

Zinc is another nutritional element that may provide antioxidative activity. The presence or absence of zinc may affect oxidative stress-related atherosclerotic processes such as disturbed NO and NF-KBrelated signaling, impaired endothelial functioning, and oxidative low-density lipoprotein (LDL) modification (Choi et al., 2018). A deficiency in zinc has been cited as a contributor to atherosclerosis in some studies, with an inverse relationship being found between atherosclerosis and the serum zinc/24-h urine zinc loss ratio (Giannoglou et al., 2010). A low intake of zinc has been associated with greater carotid intima-media thickness (CIMT) in some adults(Choi et al., 2018). Another study proposed that zinc should be used as a biological marker of cardiovascular health due to its impacts on homeostasis (Knez and Glibetic, 2021). In contrast, one of the latest meta-analyses on preventive interventional trials found that zinc exerted no remarkable impact on CVD prevention (Schwingshackl et al., 2017).

Manganese is another dietary mineral that may affect the course of atherosclerosis; however, limited data are available. One study reported that normal and atherosclerotic aortic tissues were similar in terms of manganese content(Li and Yang, 2018). On the other hand, epidemiologic research indicates increased serum manganese concentrations in individuals with atherosclerosis (Rambousková et al., 2013, llyas and Shah, 2016). It appears that manganese is essential at trace levels, whereas excessive concentrations are toxic. In fact, some have suggested a U-shaped association of manganese with the 
generation of ROS, oxidative stress, and the associated diseases (Li and Yang, 2018). However, further biomolecular and population-based data are needed to confirm such theories.

According to a number of studies, vitamin $\mathrm{C}$ exerts a positive effect in minimizing CVD risk (Cammisotto et al., 2021). At doses above $500 \mathrm{mg} /$ day, this vitamin was found to positively affect endothelial function, with its effect being more pronounced among individuals at greater risk of CVD (i.e., those with heart failure, diabetes mellitus, or atherosclerosis) (Ashor et al., 2014). Furthermore, cardiovascular risk factors such as cigarette use and diabetes mellitus have been associated with low blood levels of vitamin $\mathrm{C}$ (Toledo-lbelles and Mas-Oliva, 2018).

Vitamin E acts as a potent antioxidant and has eight stereoisomers. One of them, a-tocopherol, shows bioactivity in the human body. Supplementation with this vitamin for preventing CVDs remains a matter of controversy. A meta-analysis of 16 clinical trials found that vitamin E supplementation markedly reduced the rate of myocardial infarction in the treated subjects compared to controls (Loffredo et al., 2015). In population-based studies, at similar blood cholesterol levels, increased dietary vitamin $\mathrm{E}$ has been consistently linked with greater plasma antioxidant levels and decreased CVD risk (Lönn et al., 2012). Nonetheless, a meta-analysis of 15 trials with 188,209 individuals revealed that vitamin $E, \beta-$ carotene, and vitamin $\mathrm{C}$ supplementation revealed no protective effects against the occurrence of major cardiovascular events, myocardial infarction, cerebrovascular accidents, all-cause mortality, and cardiac mortality (Cammisotto et al., 2021).

Retinoic acid or vitamin A1 is involved in cardiogenesis signaling, with some evidence also indicating an association between this vitamin and CVDs. A study in Finland on an adult male population found that decreased levels of $\beta$-carotene, as a precursor to vitamin $A$, were linked with a higher rate of cardiovascular deaths, particularly in cigarette smokers (Karppi et al., 2012). Another study linked lower blood retinoic acid concentrations with a higher risk of death among coronary artery disease patients (Liu et al., 2016). In contrast, the Alpha-Tocopherol, Beta-Carotene Cancer Prevention (ATBC) long-term (five to eight years) cohort study on 23,144 male smokers found that a-tocopherol (50 mg per day) and/or $\beta$ carotene (20 mg per day) supplementation exerted no impact on the occurrence of myocardial infarction or cardiovascular-related death (Lee et al., 1999).

\section{Dietary antioxidant indices and risk of non-communicable diseases}

The DAQ and DAl contain the six most potent dietary antioxidants. These antioxidants have been investigated alone and in combination with each other and with alternative micronutrients to determine their effects on CVD, tbut few studies have made use of the mentioned antioxidant indices. Here, we will briefly discuss our results in relation to the related literature.

According to a multi-adjusted model, the DAI had a significant effect on minimizing CVD risk (Vahid et al.). Furthermore, one investigation examined the relationship of the DAQS with cardiovascular fitness and blood pressure, revealing a marked rise in maximum oxygen uptake when moving from the lower to 
upper DAQS tertiles with and without adjusting for confounding variables. It also showed a nonsignificant increase in blood pressure in the top DAQS tertile, after adjusting for confounders(Shahinfar et al., 2020a). Anotherinvestigation established a significant association between gastric neoplasms and poor dietary antioxidant indices, highlighting the need for nutritional antioxidants (Vahid et al., 2020). Furthermore, another study found that the risk of multiple sclerosis was double in individuals with low DAl values. That study found an important dose-response pattern, concluding that adequate dietary antioxidant intake might reduce the risk of developing multiple sclerosis (Abdollahpour et al., 2020). Finally, lower odds of having non-alcoholic fatty liver disease were associated with higher DAl values with and without adjustments for confounding variables (Vahid et al., 2021a). These results highlight the same pattern as that observed in our study, indicating that dietary antioxidants work together to reduce the risk of many non-communicable diseases.

\section{Limitation}

One limitation of our study is the indices; we did not consider some of non-nutritive antioxidant like carotenoids or polyphenols with anti-oxidant properties and just considered some major antioxidants. Another limitation was the cross-sectional design of the study of the baseline data collection for a population-based cohort, that cannot represent causal effects of the variables.

\section{Conclusion}

The role of anti-oxidants in reducing the odds of cardiovascular disease is very important. Our results highlighted the fact that DAQS and DAl had protective effects on the odds of atherosclerosis. Thus, it is suggested that dietary anti-oxidants as vitamins A, E and C, zinc, Manganese, and selenium should be taken to reduce the risk of the disease. It will be advantageous to investigate the sensitivity and specificity of DAI in different aspects in order to apply them in clinical works.

\section{Declarations}

\section{Acknowledgements}

The authors are grateful to the officers and data management staff of Kharameh cohort. This article is part of the Persian cohort study in Kharameh. Also, The authors would like to thank Center for Development of Clinical Research of Nemazee Hospital and Dr. Nasrin Shokrpour for editorial assistance.

\section{Availability of data and materials}

The datasets used and analyzed during the current study are available by sending an email to the owner of data (Abbas Rezaianzadeh)

\section{Consent for publication}

Not Applicable. 


\section{Competing interests}

The authors report no conflict of interest.

\section{Authors' contributions}

Study concept and design: PK; Acquisition of data: MGJ, AR, SVH, and RR; Analysis and interpretation of data: $\mathrm{PK}$, and $\mathrm{MJ}$; Drafting of the manuscript: $\mathrm{PK}$, and MJ; Critical revision of the manuscript for important intellectual content: PK, MJ, and MGJ; Statistical analysis: PK, and MJ; Administrative, technical, and material support: MGJ, AR, SVH, and RR; Study supervision: MGJ, AR, SVH, and RR. All authors have read and approved the final manuscript.

\section{Ethical issues}

The study was approved by ethics committee and confirmation were taken from Shiraz University of Medical Sciences (ethical code: IR.SUMS.REC.1393.S7421). Confidentiality of their personal data was emphasized.

\section{References}

1. ABDOLLAHPOUR I, NEDJAT S, SALIMI Y, MANSOURNIA MA, VAHID F, WEINSTOCK-GUTTMAN B. 2020. The role of dietary antioxidant index and index of nutritional quality in MS onset: finding from an Iranian population-based incident case-control study. Nutritional neuroscience, 1-8.

2. ARANCETA J, SERRA-MAJEM L, PÉREZ-RODRIGO C, TOJO LLOPIS,JMATAIX,JRIBAS,L, R. \& TUR, JA J. P. H. N. 2001. Vitamins in Spanish food patterns: the eVe Study. 4, 1317-1323.

3. ASHOR AW, LARA J, MATHERS, J. C. \& SIERVO M. Effect of vitamin C on endothelial function in health and disease: a systematic review and meta-analysis of randomised controlled trials. Atherosclerosis. 2014;235:9-20.

4. BISTRIAN BR. Modern nutrition in health and disease. LWW; 2006.

5. CAMMISOTTO V, NOCELLA C, BARTIMOCCIA S, SANGUIGNI V, FRANCOMANO D, SCIARRETTA S, PASTORI D, PERUZZI M, CAVARRETTA E, D'AMICO A. The role of antioxidants supplementation in clinical practice: focus on cardiovascular risk factors. Antioxidants. 2021;10:146.

6. CHOI S, LIU X, PAN Z. Zinc deficiency and cellular oxidative stress: prognostic implications in cardiovascular diseases. Acta Pharmacol Sin. 2018;39:1120-32.

7. FLORES-MATEO G, NAVAS-ACIEN A, PASTOR-BARRIUSO R, GUALLAR E. Selenium and coronary heart disease: a meta-analysis. Am J Clin Nutr. 2006;84:762-73.

8. GIANNOGLOU GD, KONSTANTINOU DM, KOVATSI L, CHATZIZISIS YS, MIKHAILIDIS DP. Association of reduced zinc status with angiographically severe coronary atherosclerosis: a pilot study. Angiology. 2010;61:449-55. 
9. ILYAS A, SHAH MH. Multivariate statistical evaluation of trace metal levels in the blood of atherosclerosis patients in comparison with healthy subjects. Heliyon. 2016;2:e00054.

10. JENKINS DJ, KITTS D, GIOVANNUCCI EL, SAHYE-PUDARUTH S, PAQUETTE M, MEJIA BLANCO, PATEL S, TSIRAKIS DKAVANAGH,M, T. \& KENDALL CW. Selenium, antioxidants, cardiovascular disease, and all-cause mortality: a systematic review and meta-analysis of randomized controlled trials. Am J Clin Nutr. 2020;112:1642-52.

11. KARPPI J, MÄKIKALLIO LAUKKANEN,J, RONKAINEN T, K. \& KURL S. Low $\beta$-carotene concentrations increase the risk of cardiovascular disease mortality among Finnish men with risk factors. Nutr Metabolism Cardiovasc Dis. 2012;22:921-8.

12. KNEZ M, GLIBETIC M. 2021. Zinc as a Biomarker of Cardiovascular Health. Frontiers in Nutrition, 8.

13. LEE I-M, COOK, N. R., MANSON, J. E., BURING, J. E. \& HENNEKENS CH. $\beta$-Carotene supplementation and incidence of cancer and cardiovascular disease: the Women's Health Study. J Natl Cancer Inst. 1999;91:2102-6.

14. LI L, YANG X. 2018. The essential element manganese, oxidative stress, and metabolic diseases: links and interactions. Oxidative medicine and cellular longevity, 2018.

15. LIU Y, CHEN H, MU D, LI D, JIANG ZHONG,Y, ZHANG N, Y. \& XIA M. Association of serum retinoic acid with risk of mortality in patients with coronary artery disease. Circul Res. 2016;119:557-63.

16. LOFFREDO L, PERRI L, CASTELNUOVO DI, IACOVIELLO A, DE GAETANO L, G. \& VIOLI F. Supplementation with vitamin $\mathrm{E}$ alone is associated with reduced myocardial infarction: a metaanalysis. Nutr Metabolism Cardiovasc Dis. 2015;25:354-63.

17. LÖNN ME, DENNIS, J. M. \& STOCKER R. Actions of "antioxidants" in the protection against atherosclerosis. Free Radic Biol Med. 2012;53:863-84.

18. LORENZON DOS SANTOS J, SCHAAN DE QUADROS A, WESCHENFELDER C, BUENO GAROFALLO S, MARCADENTI A. Oxidative stress biomarkers, nut-related antioxidants, and cardiovascular disease. Nutrients. 2020;12:682.

19. LUUHUNG N. Are dietary antioxidant intake indices correlated to oxidative stress and inflammatory marker levels?: Mary Ann Liebert, Inc. 140 Huguenot Street, 3rd Floor New Rochelle. NY 10801 USA; 2015.

20. MIRMIRAN P, MEHRABI ESFAHANI,FH, HEDAYATI Y, M. \& AZIZI, F J. P. H. N. 2010. Reliability and relative validity of an FFQ for nutrients in the Tehran lipid and glucose study. 13, 654-662.

21. ORGANIZATION WH. 2021. Cardiovascular diseases [Online]. Available: https://www.who.int/healthtopics/cardiovascular-diseases\#tab=tab_1 [Accessed 10.19.2021].

22. POUSTCHI H, KAMANGAR EGHTESAD,S, ETEMADI F, KESHTKAR A, HEKMATDOOST A-A, MOHAMMADI A, MAHMOUDI Z, SHAYANRAD Z, A. \& ROOZAFZAI FJAJOE. 2018. Prospective epidemiological research studies in Iran (the PERSIAN Cohort Study): rationale, objectives, and design. 187, 647-655.

23. RAMBOUSKOVÁ J, SLAVÍKOVÁ KRSKOVÁ,A, ČEJCHANOVÁ M, WRANOVÁ M, PROCHÁZKA K, B. \& ČERNÁ M. Trace elements in the blood of institutionalized elderly in the Czech Republic. Arch 
Gerontol Geriatr. 2013;56:389-94.

24. REES K, HARTLEY L, DAY C, FLOWERS N, CLARKE, A. \& STRANGES S. 2013. Selenium supplementation for the primary prevention of cardiovascular disease. Cochrane Database of Systematic Reviews.

25. REZAIANZADEH A, JAFARI F, SADEGHI SE, RAHIMIKAZEROONI S, BAHRAMALI E, KARAMI H. 2021. Awareness, Treatment, and Control of Hypertension Among 10663 Adults in Kherameh: A PopulationBased Study.

26. REZAZADEH A, RASHIDKHANI BJJONS, VITAMINOLOGY. The association of general and central obesity with major dietary patterns of adult women living in Tehran. Iran. 2010;56:132-8.

27. RIVAS A, ROMERO A, MARISCAL-ARCAS M, LÓPEZ MONTEAGUDO,C, OCAÑA-PEINADO G. F. \& OLEASERRANO, F. 2012. Association between dietary antioxidant quality score (DAQs) and bone mineral density in Spanish women. Nutr Hosp, 27, 1886-93.

28. ROTH GA, MENSAH GA, JOHNSON CO, ADDOLORATO G, AMMIRATI E, BADDOUR LM, BENJAMIN BARENGO,NC,BEATON,AZ, E. J. \& BENZIGER CP. Global burden of cardiovascular diseases and risk factors, 1990-2019: update from the GBD 2019 study. J Am Coll Cardiol. 2020;76:2982-3021.

29. SARRAFZADEGAN N, MOHAMMMADIFARD N. Cardiovascular disease in Iran in the last 40 years: prevalence, mortality, morbidity, challenges and strategies for cardiovascular prevention. Arch Iran Med. 2019;22:204-10.

30. SCHWINGSHACKL L, BOEING H, STELMACH-MARDAS M, GOTTSCHALD M, DIETRICH S, HOFFMANN G, CHAIMANI A. Dietary Supplements and Risk of Cause-Specific Death, Cardiovascular Disease, and Cancer: A Systematic Review and Meta-Analysis of Primary Prevention Trials. Adv Nutr. 2017;8:2739.

31. SHAHINFAR H, SHAHAVANDI M, DJAFARIAN JIBRIL,AT, CLARK K, C. C. \& SHAB-BIDAR S. The association between dietary antioxidant quality score and cardiorespiratory fitness in Iranian adults: a cross-sectional study. Clin Nutr Res. 2020a;9:171.

32. SHAHINFAR H, SHAHAVANDI M, DJAFARIAN JIBRIL,AT, CLARK K, C. C. \& SHAB-BIDAR, S J. C. N. R. 2020b. The association between dietary antioxidant quality score and cardiorespiratory fitness in Iranian adults: a cross-sectional study. 9, 171.

33. TOLEDO-IBELLES P, MAS-OLIVA J. Antioxidants in the fight against atherosclerosis: is this a dead end? Curr Atheroscler Rep. 2018;20:1-12.

34. TUR JA, SERRA-MAJEM L, ROMAGUERA D, PONS AJEJON. 2005. Does the diet of the Balearic population, a Mediterranean type diet, still provide adequate antioxidant nutrient intakes? 44, 204213.

35. VAHID F, NASIRI Z, ABBASNEZHAD A, MOGHADAM EF. Antioxidant potential of diet: Association between dietary antioxidant index and odds of coronary heart disease: A case-control study. Mediterranean Journal of Nutrition and Metabolism, 1-13.

36. VAHID F, RAHMANI D, DAVOODI SH. Validation of Dietary Antioxidant Index (DAI) and investigating the relationship between DAI and the odds of gastric cancer. Nutr Metabolism. 2020;17:1-9. 
37. VAHID F, RAHMANI D, HEKMATDOOST A. The association between dietary antioxidant index (DAI) and nonalcoholic fatty liver disease (NAFLD) onset; new findings from an incident case-control study. Clin Nutr ESPEN. 2021a;41:360-4.

38. VAHID F, RAHMANI D, HEKMATDOOST AJCNE. 2021b. The association between dietary antioxidant index (DAI) and nonalcoholic fatty liver disease (NAFLD) onset; new findings from an incident casecontrol study. 41, 360-364.

39. WORLD HEALTH ORGANIZATION. 11. June 2021. Cardiovascular diseases (CVDs) [Online]. Available: https://www.who.int/news-room/fact-sheets/detail/cardiovascular-diseases-(cvds) [Accessed 2021].

40. WRIGHT ME, MAYNE ST, STOLZENBERG-SOLOMON RZ, LI Z, PIETINEN P, TAYLOR PR, VIRTAMO, J. \& ALBANES D. Development of a comprehensive dietary antioxidant index and application to lung cancer risk in a cohort of male smokers. Am J Epidemiol. 2004;160:68-76.

41. ZAMANI N. HAJIFARAJI, M., MALEKSHAH, A. F.-T., KESHTKAR, A. A., ESMAILLZADEH, A. \& MALEKZADEH RJ. A. O. I. M. 2013. A case-control study of the relationship between gastric cancer and meat consumption in Iran. 16, 0-0. 